\title{
Em defesa de uma sociologia em escala individual
}

\section{Paulo Eduardo Moruzzi Marques'}

\section{Resenha do livro:}

LAHIRE, Bernard. Dans les plis singuliers du social: individus, institutions, socialisations. Paris, Éditions La Découverte, 2013.

A obra de Bernard Lahire ${ }^{2}$ constitui um convite para olhar por ângulos estimulantes o campo de debates em torno de questões centrais para a sociologia. Seu recente livro, Dans les plis singuliers du social, é concebido como meio de tornar mais visível o sentido geral de seu trabalho. Em relação a outros títulos do autor (Lahire, 2002; 2005; 2012), trata-se de um texto mais condensado, cujo eixo de reflexão gira em torno dos desdobramentos do social nos indivíduos.

No livro, Lahire defende insistentemente que é de grande interesse para as ciências sociais focalizar a "fabricação social do indivíduo", o que significa realizar uma sociologia em escala individual. De fato, seu estudo minucioso sobre a teoria do habitus (Lahire, 2001), ou seja, a ideia de um social incorporado sob forma de disposições duráveis para agir, sentir e acreditar, o leva a desenvolver sua proposta de exame do mundo social a partir da escala do indivíduo.

Para tal propósito, o autor desenvolve inicialmente uma análise sobre o lugar dos indivíduos nas ciências sociais, lembrando que durante muito tempo a

\footnotetext{
1 Programa de Pós-Graduação Interunidades (CENA-ESALQ) em Ecologia Aplicada (PPGI-EA/USP) Piracicaba/SP - Brasil - pmarques@usp.br

2 Bernard Lahire é professor de sociologia na École Normale Supérieur de Lyon e diretor do grupo de pesquisa sobre a socialização (CNRS/Université Lyon II/ENS-LSH).
} 
sociologia negligenciou o indivíduo para concentrar suas luzes em grupos, instituições e movimentos sociais. Neste sentido, a construção do campo de conhecimento da sociologia se forja com o desejo de rompimento com a psicologia, procurando explicar o "social pelo social". Em grande medida, os fundadores da disciplina situaram fora do campo do conhecimento sociológico os problemas individuais, julgados próprios à investigação psicológica ou psiquiátrica. As disciplinas destes últimos campos deveriam se encarregar dos indivíduos, mas não as ciências sociais, em particular a sociologia.

Deixando, portanto, pensar por muito tempo que os indivíduos, com seus temperamentos, comportamentos, excentricidades, pouco ou nada interferem no mundo social, a sociologia lançou poucas luzes para o fato de que os indivíduos são, finalmente, o produto das experiências sociais, na família, na escola e em todas as instituições. Nesta linha de raciocínio, Lahire discute a concepção de Durkheim segundo a qual a sociologia se interessa pelos fatos exteriores aos indivíduos. Com efeito, poderíamos adequadamente pensar esta exterioridade como realidade que nos é preexistente e na qual cada um de nós está mergulhado. Efetivamente, não se inventa a língua, a moeda, o casamento, o direito (em suma o conjunto das instituições econômicas, políticas, culturais, religiosas e morais) a cada geração.

Porém, é indigesta a formulação de Durkheim (1973) segundo o qual as maneiras coletivas de agir e de pensar constituem uma realidade situada fora dos indivíduos que, em cada momento do tempo, conformam-se a tal situação. De fato, as maneiras preexistentes de agir e pensar sobrevivem aos indivíduos justamente em razão destes últimos incorporarem e carregarem desde o nascimento até a morte tais maneiras de agir, pensar e sentir.

Com sua abordagem, Durkheim concebe uma personificação do coletivo, dotando o social de atributos classicamente ligados aos indivíduos (tais como espírito e consciência), o que incomodará em grande medida os estudos sociológicos posteriores. Lahire considera que o emprego destas expressões pode ser sociologicamente útil, enquanto metáfora, para assinalar desta maneira que existem por exemplo hábitos, crenças ou sentimentos mais ou menos compartilhados por um grupo social sob o efeito das condições comuns de vida material, simbólica, educativa e/ou religiosa.

Nesta reflexão sobre as relações indivíduo e sociedade, Lahire se apoia na obra de Norbert Elias (1994) para esclarecer inicialmente que nossos meios linguísticos conduzem frequentemente a uma concepção atomizada segundo a qual indivíduo e sociedade são realidades distintas. Para favorecer outro olhar sobre tal relação, Elias propõe o conceito, central em sua obra, de "interdependência". 
Assim, seus estudos sociais focalizam as configurações históricas de relações de interdependência que produzem os indivíduos os quais, por sua vez, contribuem para a existência dinâmica destas relações.

Desta maneira, a consciência de um indivíduo toma forma (desde a socialização na infância) nas relações de interdependência com os outros e com os produtos objetivados das atividades humanas. Portanto, insiste Lahire, o comportamento individual não é nem produto de uma pura interioridade nem tampouco o efeito de um contexto exterior, mas o fruto das relações passadas e presentes de interdependência agindo sobre o indivíduo. Se é pertinente pensar em comportamento individualista, este fenômeno não coloca em questão a "fabricação social do indivíduo", ou seja, o caráter socialmente determinado do comportamento individual pelas forças das instituições, dos quadros socializadores e das normas de convívio social.

A propósito, Bernard Lahire retoma neste livro uma linha de reflexão que foi mais desenvolvida em sua obra anterior (Lahire, 2012). Trata-se de seu desejo de que os estudos sociais desenvolvam um equilíbrio explicativo entre as propriedades sociais incorporadas pelos atores e aquelas objetivadas nos contextos de ação. De maneira pertinente, o autor propõe que uma via estimulante de pesquisa sobre as práticas e comportamento dos indivíduos deve tomar em consideração tanto uma reconstrução dos tipos de disposições mentais e comportamentais incorporados pelos atores graças à interiorização de experiências sociais passadas quanto as características particulares do contexto da ação. Nesta ótica, Lahire considera pouco frutífero a polarização sociológica entre a ênfase excessiva nas disposições incorporadas e o foco exclusivo no contexto da ação (tal como frequentemente deixa pensar a corrente pragmática), o que responderia antes de tudo às lógicas de concorrência e distinção no campo científico.

Para representar sua proposta, Lahire elabora formulações que explicitem tanto as disposições ou o passado incorporado quanto o contexto presente. As práticas dos atores podem assim ser pensadas como o resultado de uma equação cujas variáveis são o quadro contextual que pesa sobre aqueles envolvidos (as exigências das situações) e as disposições socialmente constituídas.

Nesta ordem de ideias, Lahire salienta, então, o interesse sociológico de evidenciar as inúmeras variações das práticas no âmbito de uma "sociologia da pluralidade disposicional e contextual". De um lado, a socialização passada no seio de um mesmo ator é heterogênea, o que resulta em múltiplas disposições, muitas vezes contraditórias, e, de outro lado, os contextos de atualização destas disposições são muito variados. 
O livro instiga então a uma reflexão sobre os mecanismos subtis de ativação ou inibição das múltiplas disposições incorporadas pelos indivíduos em razão da frequentação de uma pluralidade de contextos sociais. Deste modo, a ativação de uma ou outra disposição em determinado contexto é o produto da interação entre forças internas e externas. Em outras palavras, trata-se de conceber relações de forças entre disposições mais ou menos interiorizadas ao longo da socialização no passado (forças internas) e elementos do contexto que pesam sobre o desenrolar da ação (forças externas).

Com esta perspectiva, Lahire estima que um determinismo fundado unicamente sobre o meio social de origem é redutor e impotente para tudo explicar. Assim, o autor propõe uma análise sociológica mais subtil, que permita investigar a relação entre o social incorporado (em razão do meio familiar, da formação escolar etc.) e os contextos relacionais, práticos e institucionais nos quais o social incorporado é estimulado a se atualizar.

Se as pesquisas realizadas sobre grandes populações permitem oferecer um quadro simplificado de comportamentos ligados às condições sociais associadas a faixas etárias, gênero, origem social, formação profissional, Lahire nos convida a examinar mais de perto a complexidade dos fatores que intervêm sobre cada indivíduo singular (singularidade, aliás, que é também produto do social) em razão do entrelaçamento de disposições e de condições variáveis para seu acionamento. Em nossas sociedades muito diferenciadas, os indivíduos frequentam muito comumente vários tipos particulares de ambientes socialmente constituídos. Nesta linha, a sociologia em escala individual proposta por Bernard Lahire deve considerar que os indivíduos atravessam diferentes esferas de atividades em contextos distintos, o que permite levantar muitas questões instigantes: Como a diversidade exterior é incorporada nos indivíduos? Como experiências socializadoras distintas, e mesmo contraditórias, podem coabitar um mesmo corpo? Como tais experiências se estabelecem mais ou menos profundamente em cada um e como elas intervêm em diferentes momentos da vida social dos indivíduos?

No penúltimo capítulo do livro, Lahire desenvolve ideias visando tratar desta fabricação social dos indivíduos a partir de uma reflexão sobre os processos de socialização. $O$ autor propõe que estes últimos podem ser pensados em termos da transformação de um ser biológico em ser social graças ao efeito de múltiplas interações desde seu nascimento com outros indivíduos e com todo o mundo material produzido pela história.

Com este ponto de partida, Bernard Lahire pondera que a noção de socialização, para ter uma efetiva utilidade sociológica, muito além de lembrar o 
caráter socialmente construído dos atores individuais, deve conduzir a análises finas dos quadros (instâncias, instituições), modalidades (formas, técnicas), tempos (momentos da vida, duração, intensidade) e efeitos (disposições a acreditar, sentir, agir) dos processos socializadores. De forma bem fundamentada, Lahire propõe que a socialização passa assim de uma noção "amorfa" para um conceito científico susceptível de ser mobilizado para o desenvolvimento de estudos precisos de casos, o que exige notadamente a realização de entrevistas longas e a observação direta de comportamentos.

Com esta ótica, o autor assinala a importante distinção realizada no âmbito da sociologia entre a socialização primária (no seio da família) e secundária (nas escolas, nos universos profissionais, nas instituições políticas, religiosas, culturais, esportivas etc.). Esta importância se associa às particularidades da socialização primária, quando a criança incorpora um único mundo concebível na mais ampla e completa dependência social e afetiva em relação aos adultos que a cercam. Trata-se de um processo intenso, precoce e, por muito tempo, sem concorrência, o que explica o peso da origem social em termos de comportamentos e preferências. Mesmo se a família detém cada vez menos o monopólio da educação infantil, ela continua a exercer um papel de filtro no que se refere às escolhas de diferentes naturezas em torno da criança. Porém, neste ponto, Lahire adverte que o universo familiar não é homogêneo na medida em que os cônjuges não compartilham, na maior parte das vezes, as mesmas propriedades sociais (origem, posição, nível e tipo de formação), o que tem consequências na socialização das crianças. Por outro lado, a precocidade cada vez maior da frequentação de universos sociais distintos da família pelas crianças, notadamente pelo acesso crescente da mulher no mundo profissional, permite levantar questões sobre a sucessão primária-secundária da ação socializadora.

Seja como for, as sociedades profundamente diferenciadas, com padrões de socialização muito distintos, levam à "fabricação" de um patrimônio de disposições incorporadas nos indivíduos bastante heterogêneo. Com tal concepção, a análise de quais disposições são ativadas ou inibidas em diferentes contextos de ação pode se tornar mais perspicaz.

No último capítulo de seu livro, Lahire se alimenta do conhecimento produzido pelas neurociências, iluminando o efeito decisivo das interações sociais no organismo humano, para reforçar suas interpretações. Nesta linha, o autor discorre sobre a imprescindibilidade dos processos de socialização em razão da imaturidade biológica da criança, aspecto muito específico da espécie humana. Com efeito, nosso cérebro se caracteriza por ter um desenvolvimento muito lento de sua forma final, propriedade que torna as crianças extremamente 
vulneráveis. Desta forma, elas são, por um longo tempo, dependentes dos adultos, tornando a socialização uma etapa indispensável, longa e custosa para a formação de indivíduos bem integrados socialmente.

Enfim, este livro de Bernard Lahire oferece muitos elementos para uma reflexão fecunda sobre as relações sociais a partir de um foco no indivíduo. Sua defesa de uma sociologia em escala individual se constrói de maneira muito instigante, fornecendo muitas luzes para que o olhar sociológico seja mais profundo e elucidativo.

\section{Referências}

DURKHEIM, Émile. As regras do método sociológico. Os pensadores, vol. XXXIII, Tradução de Margarida Garrido Esteves. São Paulo, Abril, 1973.

ELIAS, Norbert. A sociedade dos indivíduos. Rio de Janeiro, Jorge Zahar Ed., 1994.

LAHIRE, Bernard. Le travail sociologique de Pierre Bourdieu: dettes et critiques. Paris, La Découverte, 2001.

LAHIRE, Bernard. O homem plural: os determinantes da ação. Petrópolis, Vozes, 2002. LAHIRE, Bernard. L'esprit sociologique. Paris, La Découverte, 2005.

LAHIRE, Bernard. Monde pluriel: penser l'unité des sciences sociales. Paris, Seuil, 2012.

Recebida em 25/06/2015

Aprovada em 14/12/2015

\section{Como citar esta resenha:}

MARQUES, Paulo Eduardo Moruzzi. Em defesa de uma sociologia em escala individual. Contemporânea - Revista de Sociologia da UFSCar, v. 6, n. 2, jul.-dez. 2016, pp. 487-492. 